\title{
Absence of the dawn phenomenon and abnormal lipolysis in Type 1 (insulin-dependent) diabetic patients with chronic growth hormone deficiency
}

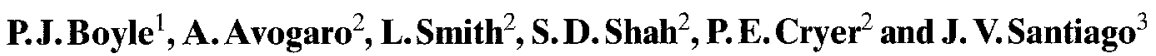 \\ ${ }^{\prime}$ Division of Endocrinology, Department of Medicine, The University of New Mexico, Albuquerque, New Mexico, Metabolism Divisions of \\ the Departments of ${ }^{2}$ Medicine and ${ }^{3}$ Pediatrics and the General Clinical Research Center and Diabetes Research and Training Center, \\ Washington University School of Medicine, St. Louis, Missouri, USA
}

\begin{abstract}
Summary. To determine the role of growth hormone in overnight insulin requirements and lipolysis, five patients with chronic growth hormone deficiency and Type 1 (insulindependent) diabetes mellitus and six control patients with diabetes were each studied on two separate nights. Insulin was infused at a variable rate throughout one night to maintain euglycaemia and fixed at 04.00 hours on another. During the variable infusion, euglycaemia was maintained in control patients by a $36 \%$ increase in insulin infusion rate between 03.00 and 08.00 hours while a $46 \%$ decrease in the rate was required in growth hormone deficient patients $(p<0.02)$. Despite this difference, mean free insulin values were equivalent. This finding is suggestive of increased insulin clearance in growth hormone sufficient patients. Glucose levels rose in control and fell in growth hormone deficient patients
\end{abstract}

when insulin infusion rates were fixed at 04.00 hours. Glycerol production and non-esterified fatty acid concentrations were significantly lower in the growth hormone deficient diabetic patients, $p<0.001$, and when normalized with a heparin infusion, had no effect on insulin requirements. We conclude that: (1) growth hormone contributes to the development of the "dawn phenomenon," possibly by increasing insulin clearance (2) growth hormone helps sustain nocturnal lipolysis in Type 1 diabetes and (3) non-esterified fatty acids are not involved in the dawn phenomenon.

Key words: Dawn phenomenon, lipolysis, growth hormone, Type 1 (insulin-dependent) diabetes mellitus, peripheral glucose utilization.
Rates of insulin replacement must increase during the early morning hours in most patients with Type 1 (insulindependent) diabetes mellitus if nocturnal euglycaemia is to be maintained. Clarke et al. [1] were among the first to investigate the potential mechanisms involved in this process, now referred to as "dawn phenomenon". When the term was coined in 1981 [2], Schmidt ascribed the increase in nocturnal insulin requirement to a group of factors which also included waning of insulin absorption from the last subcutaneous injection. Our current use of the term "the dawn phenomenon" refers to the relative fasting hyperglycaemia that results when insulin infusion rates, adequate to provide euglycaemia during the middle of the night, are fixed through the pre-breakfast hours.

There are a multitude of metabolic changes which occur during sleep that have been postulated to provide the genesis of the dawn phenomenon. Nocturnal increments in cortisol [3], adrenocorticotropin [4] and catecholamines [5] have been investigated and eliminated from the list of potential candidates capable of inducing a dynamic change in glucose production or leading to a state of relative insulin resistance during the pre-breakfast hours or dawn period. Plasma glucagon concentration tends to decrease or remain unchanged during the night $[4,5]$ and as such would not contribute to increments in hepatic glucose output. In studies designed to mimic isolated growth hormone deficiency by infusion of somatostatin with fixed replacement of insulin and glucagon to achieve levels comparable to those seen in portal blood, Campbell et al. [5] observed only a slight rise in plasma glucose by morning. But, when boluses of growth hormone were given repeatedly under the same experimental conditions, the dawn phenomenon was reproduced. Although the idea that the dawn phenomenon is somehow related to the normal nocturnal bursts of growth hormone secretion is an attractive one, not all studies designed to investigate this issue have concurred $[6,7]$.

We tested the hypotheses that rates of insulin replacement required to maintain euglycaemia would not increase during the pre-breakfast period in patients with Type 1 diabetes and chronic growth hormone deficiency when compared to a matched group of diabetic patients with normal pituitary function, and that when insulin was held constant the former patients would not exhibit a pre- 
breakfast increase in plasma glucose levels. In addition, because normal nocturnal increments in growth hormone have been implicated in helping to sustain lipolysis during sleep in non-diabetic individuals [8], glycerol turnover studies were performed in the same diabetic groups to assess the degree to which rates of lipolysis are impaired when growth hormone deficiency is superimposed on the well-controlled diabetic state. Recent studies in humans $[9,10]$ indicated that non-esterified fatty acids (NEFA) may compete with glucose for peripheral utilization and as such may indirectly contribute to hyperglycaemia. To the extent that rates of lipolysis, and consequently NEFA levels, are reduced in the absence of growth hormone in the setting of Type 1 diabetes, we wondered whether normalization of NEFA concentrations during the night would increase insulin requirements during the dawn period. To address this issue, growth hormone deficient patients had their night time NEFA levels "clamped" at values comparable to those observed in the control diabetic group with a variable heparin infusion while euglycaemia was maintained with variable rate insulin infusions.

\section{Subjects, materials and methods}

\section{Subjects}

Five patients (two men and three women) with Type 1 diabetes mellitus and chronic growth hormone and cortisol deficiency (Group A) and a control group of six patients (three men and three women) with Type 1 diabetes and intact growth hormone secretion (Group B) gave their written consent to participate in studies (see below) that were approved by Washington University Human Studies Committee and conducted at the Washington University General Clinical Research Center (GCRC). Growth hormone deficiency was the result of Sheehan's syndrome in one patient, pituitary ablation (performed for proliferative retinopathy) in three and congenital hypopituitarism in one. Growth hormone deficiency (peak growth hormone $<0.7 \mathrm{ng} / \mathrm{ml}$ ) was confirmed by insulin-induced hypoglycaemia and clonidine stimulation prior to inclusion in these studies. Patients in the control group were matched for age, sex and duration of diabetes to those with growth hormone deficiency. Excluding the proliferative retinopathy present in three participants from Group A, no other major complication of diabetes (nephropathy or neuropathy based on physical examination and screening laboratory tests) was evident in these patients. Background retinopathy was noted in one other growth hormone deficient patient and in five of the control diabetic patients. All patients taking thyroid hormone replacement had normal free thyroxine concentrations. Patients with growth hormone and cortisol deficiency were switched from their usual glucocorticoid replacement to dexamethasone, $0.5 \mathrm{mg}$ in the morning and $0.25 \mathrm{mg}$ at 20.00 hours three days prior to study. Dexamethasone was selected because of its long half-life in order to reduce waning of glucocorticoid effect during the night. Ages ranged from 17 to $46[31 \pm 10(\mathrm{SD})]$ years for Group A and 20 to $40(32 \pm 8)$ years for Group B. Mean body mass index for the two groups was $27.0 \pm 3.5$ and $22.9 \pm 0.5 \mathrm{~kg} / \mathrm{m}^{2}$, respectively. Duration of diabetes was 4 to $37(23 \pm 13)$ years and 12 to $32(23 \pm 8)$ years, respectively. Mean $\mathrm{Hb}_{\mathrm{Ic}}$ was $13.8 \pm 2.6 \%$ and $12.1 \pm 2.4 \%$, respectively (normal range 4.4 to $6.3 \%$ ).

\section{Protocols}

Variable and Fixed Infusion Nights. All patients participated in two studies which were performed on consecutive nights. Intermediateacting insulin was discontinued at least $30 \mathrm{~h}$ prior to the start of the first study period. No patient was using lente or ultralente insulin.
Diabetes was managed with subcutaneous regular insulin in the morning before the first study and an intravenous infusion of regular insulin was started in the afternoon to achieve a glucose concentration of $5.6 \mathrm{mmol} / 1$ by 24.00 hours. The patients' usual diets were provided with caloric intake and composition of meals matched for the two days each subject stayed at the GCRC. (Night time snacks were excluded). Physical activity was matched in the days before each study. Patients were left undisturbed at night as much as possible. Beginning at 22.00 hours, intravenous insulin (regular, purified pork; Squibb Novo, Bagsvaerd, Denmark) was infused with a Harvard Springe Pump 22 (Harvard Apparatus Inc, South Natick, Mass., USA) with changes in rate made at 15 min intervals to maintain euglycaemia at $5.6 \mathrm{mmol} / 1$ throughout the night (variable infusion night). On the other night, the infusion rate was varied only until 04.00 hours and then fixed for each individual at the rate which was used during the immediately preceding $15 \mathrm{~min}$ (fixed infusion night). During both nights $\left[3{ }^{3} \mathrm{H}\right]$ glucose $(13.5 \mathrm{Ci} / \mathrm{mmol}$; New England Nuclear Corporation, Boston, Mass., USA) was infused intravenously $\left(0.2 \mathrm{mCi} \cdot \mathrm{min}^{-1}\right.$ following a $20 \mathrm{mCi}$ bolus at 22.00 hours $)$ to allow estimation of rates of glucose production and utilization. On the night during which the glucose concentration was held steady throughout the night, $\left[1,1-{ }^{2} \mathrm{H} 2\right]$ glycerol was infused at approximately 0.033 $\mathrm{mmol} \cdot \mathrm{kg}^{-1} \cdot \mathrm{min}^{-1}$ so that glycerol flux could be calculated. The sequence of these studies was varied. Intravenous insulin was continued during the intervening day.

NEFA clamp in growth hormone deficient diabetic patients. Four growth hormone deficient diabetic patients were restudied on a separate occasion. Withdrawal of long-acting insulin and preparation with intravenous insulin before 24.00 hours were identical to the first two evenings. Insulin infusion was varied to maintain euglycaemia throughout the night. At 02.30 hours, heparin was infused intravenously (initial rate of $0.1 \mathrm{U} \cdot \mathrm{kg}^{-1} \cdot \mathrm{min}^{-1}$ ) to coincide with the onset of growth hormone mediated increments in lipolysis seen in nondiabetic normal subjects [8]. NEFA concentrations were measured at $30 \mathrm{~min}$ intervals with a $30 \mathrm{~min}$ turn around time [11]. Theoretically, the lipoprotein lipase released by heparin infusion could lead to in vitro hydrolysis and falsely elevated fatty acid levels. However, with the doses of heparin used, we were unable to detect additional increments in fatty acid levels with prolonged incubation of the serum following the initial isolation. This is in agreement with observations by Meng and Edgren [12]. Heparin infusion rates were then adjusted in $0.01 \mathrm{U} \cdot \mathrm{kg}^{-1} \cdot \mathrm{min}^{-1}$ steps by the investigator resulting in NEFA concentrations in the range seen in the growth hormone sufficient diabetic control subjects. Heparin infusion rates ranged between 0.14 and $0.15 \mathrm{U} \cdot \mathrm{kg}^{-1} \cdot \mathrm{min}^{-1}$ by the end of the night. In the final $2 \mathrm{~h}$ of the study, infusion rates were increased to result in NEFA concentrations approximately $200 \mu \mathrm{mol} / \mathrm{l}$ in excess of the control group.

Venous blood for glucose was sampled every $15 \mathrm{~min}$ during all nights. Other observations were made at 30 min intervals from 24.00 through 08.00 hours in all studies. These included blood samples which were distributed to the appropriate tubes, kept on ice, and centrifuged promptly. The supernatants were then frozen for subsequent analysis.

Comparison of free insulin concentrations determined by immediate and delayed polyethylene glycol precipitation techniques. Six other Type 1 diabetic patients arrived fasting at the GCRC and gave informed consent to have one intravenous catheter for blood sampling inserted. After two samples for baseline, free insulin values were obtained, they then administered their usual dose of subcutaneous regular insulin and ate breakfast. Samples for free insulin were collected every $30 \mathrm{~min}$ in tubes containing EDTA and treated by both of the following methods: (1) Bedside Separation. The whole blood was spun in a microcentrifuge for $1 \mathrm{~min}$ at room temperature and an aliquot of plasma immediately added to an equal volume of $30 \%$ chilled polyethylene glycol $\left(4^{\circ} \mathrm{C}\right)$, allowed to stand on ice for $15 \mathrm{~min}$, spun in a microcentrifuge for $1 \mathrm{~min}$ and the supernate collected and frozen for subsequent analysis [13], (2) Delayed Separation. The blood was centrifuged at $4^{\circ} \mathrm{C}$ and the plasma collected and frozen for 

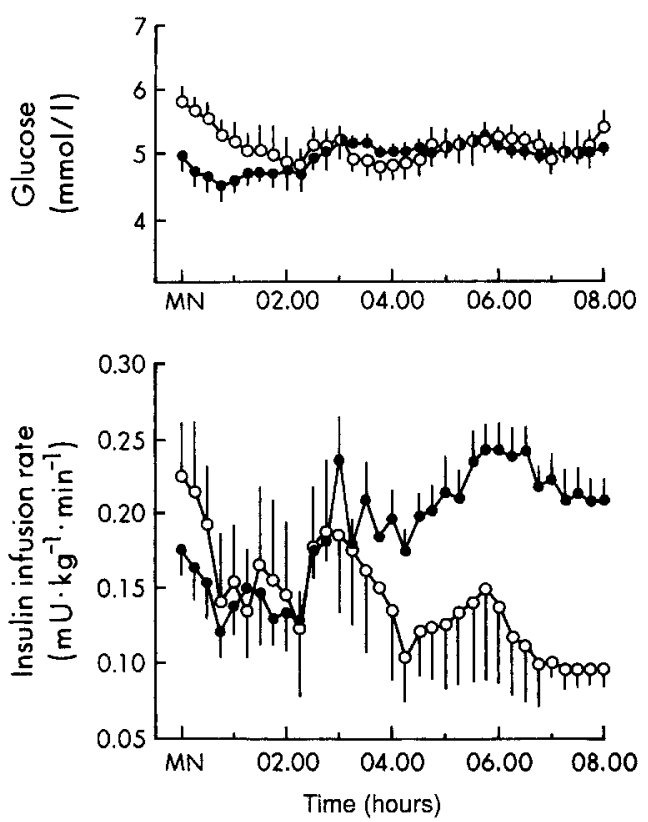

Fig. 1. Plasma glucose concentrations (upper panel) and insulin infusion requirements (lower panel) mean \pm SEM from $24.00(\mathrm{MN}$ ) to 08.00 hours (variable infusion night) in Type 1 (insulin-dependent) diabetic patients (closed symbols) and Type 1 diabetic patients with growth hormone deficiency (open symbols)

later thawing and polyethylene glycol precipitation according to the method of Kuzuya et al. [14].

\section{Analyticalmethods}

Plasma glucose was measured with a glucose oxidase method using a glucose analyser (Beckman Instruments, Inc., Fullerton, Calif., USA). Plasma free insulin and C-peptide [14], glucagon [15], growth hormone [16] and cortisol [17] were measured with radioimmunoassays, plasma norepinephrine and epinephrine with a single isotope derivative radioenzymatic method [18]. Blood $\beta$-hydroxybutyrate [19], lactate [20] and alanine [21] were measured with microfluorimetric methods. NEFAs [11] were determined by a rapid enzymatic technique. Plasma for glucose radioactivity was precipitated with perchloracetic acid and the supernatant decanted, dried and reconstituted in distilled water prior to scintillation counting; glucose production and utilization rates were calculated as described previously [22]. Glycerol concentration and flux were determined by gas-chromatographic mass spectrometry using a modification of the procedure described by Beylot et al. [23].

\section{Statistical analysis}

Data are presented as the mean \pm SEM. Insulin clearance was calculated for each individual as the mean rate of insulin infusion during the 30 min before a blood sample was obtained, divided by the individual's free insulin concentration measured at the end of that $30 \mathrm{~min}$. Rates of increase or decrease in insulin infusion rate, insulin clearance or other parameters of interest were determined by linear regression (least squares fit) for specified time spans for each individual and the slopes compared with a $t$-test for unpaired data. Areas under the curve for rates of glucose production and utilization, glycerol flux and the concentration curves of intermediary metabolites which did not change significantly over the night were determined for each individual by applying sequential trapezoidal summation between observation points and testing them for significance with an unpaired $t$-test.

\section{Results}

Variable Infusion Night

Glucose and insulin infusion requirements (Fig.1). Mean plasma glucose was slightly higher in Group A from 24.00 to 02.00 hours, but thereafter was maintained quite close to the target of $5.0 \mathrm{mmol} / \mathrm{l}$ in both groups. Decrements in insulin infusion requirements occurred in both groups from 24.00 to 02.00 hours in order to achieve the target glucose of $5.0 \mathrm{mmol} / \mathrm{l}$. Mean insulin infusion requirements were closely matched (Group B $0.13 \pm 0.20$, Group A $0.15 \pm 0.50 \mathrm{mU} \cdot \mathrm{kg} \cdot{ }^{-1} \cdot \mathrm{min}^{-1}$ ) at 02.00 hours but then diverged. Mean infusion rates for Group B increased to a maximum of $0.24 \pm 0.19$ and Group A decreased to $0.093 \pm 0.013 \mathrm{mU} \cdot \mathrm{kg}^{-1} \cdot \mathrm{min}^{-1}$ between 03.15 and 08.00 hours, $p<0.02$.

Comparison of glucose, insulin infusion rate, free insulin concentration and insulin clearance at 02.00 and 06.00 hours of variable infusion night (Fig. 2). Mean glucose concentration was not significantly different between either group at either time point. Despite an increase in insulin infusion requirement from $0.13 \pm 0.02$ to $0.24 \pm 0.02 \mathrm{mU} \cdot \mathrm{kg}^{-1} \cdot \mathrm{min}^{-1}$ in the control diabetic patients, mean free insulin concentrations between 02.00 and 06.00 hours did not change significantly. No significant difference in mean insulin infusion requirement was noted in the growth hormone deficient subjects, $0.15 \pm 0.05$ vs $0.13 \pm 0.05 \mathrm{mU} \cdot \mathrm{kg}^{-1} \cdot \mathrm{min}^{-1}(02.00$ hours vs 06.00 hours). Mean insulin clearance in the control Group A mirrored the trend for increased insulin infusion
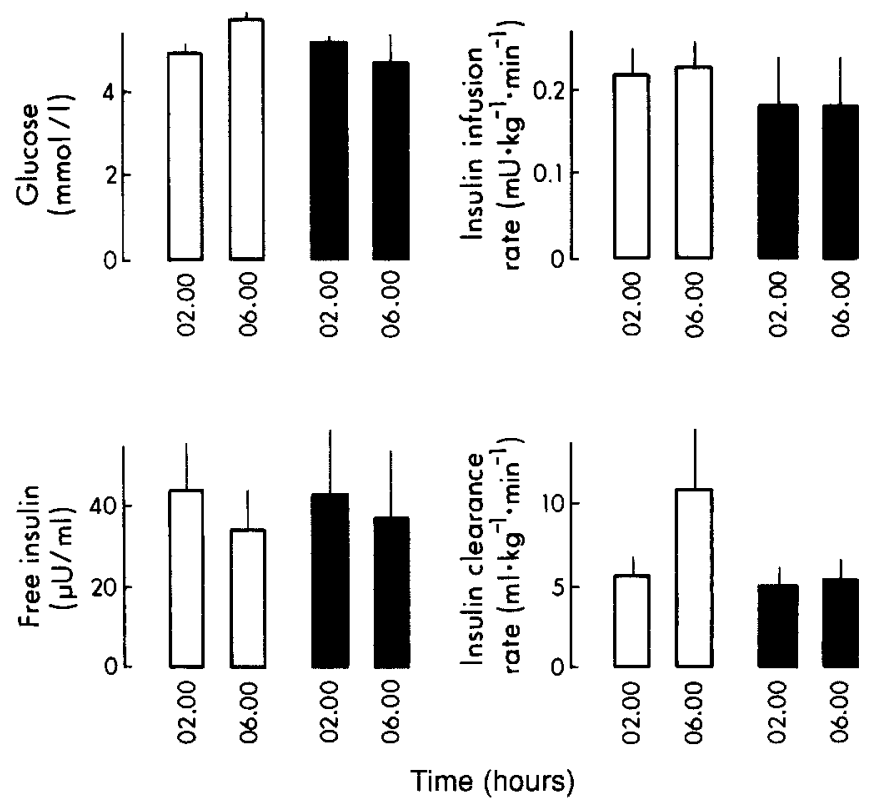

Fig. 2. Plasma glucose concentrations, insulin infusion rates, free insulin concentrations and insulin clearance rates mean \pm SEM during the variable insulin infusion night in Type 1 (insulin-dependent) diabetic patients (open columns) and Type 1 diabetic patients with growth hormone deficiency (closed columns) 


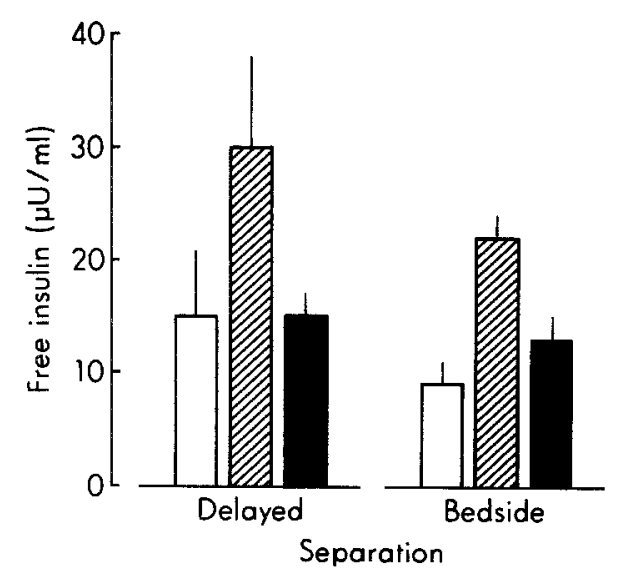

Fig.3. Comparison of mean free insulin concentrations \pm SEM by two techniques of sample preparation following subcutaneous injection of insulin in six patients with Type 1 (insulin-dependent) diabetes mellitus. Pre-injection levels (open columns), peak levels (cross-hatched columns), and increments (closed columns) are shown. Peak levels were significantly different $(p<0.001$ and $p<0.01$, respectively) from pre-injection levels; increments did not differ significantly
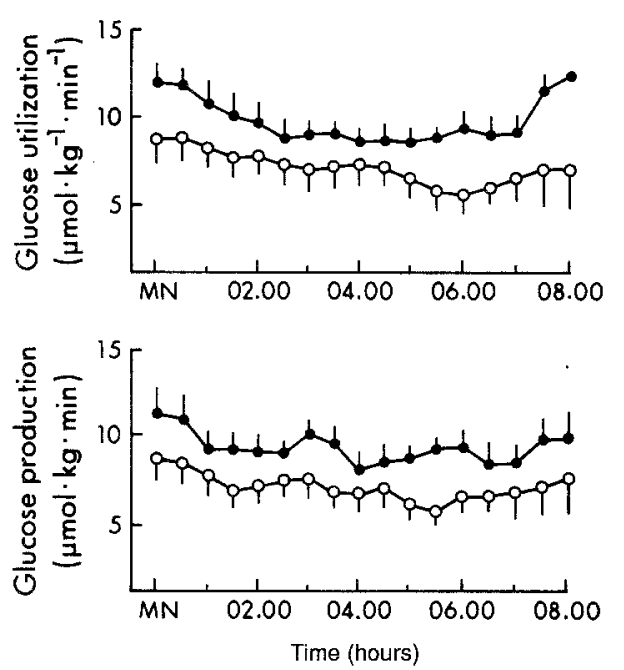

Fig. 4. Nocturnal rates of glucose utilization (upper panel) and production (lower panel) mean \pm SEM during variable infusion night (MN, 24.00 hours) in Type 1 (insulin-dependent) diabetic patients (closed symbols) and Type 1 diabetic patients with growth hormone deficiency (open symbols)

requirements, beginning at $5.6 \pm 1.8 \mathrm{ml} \cdot \mathrm{kg}^{-1} \cdot \mathrm{min}^{-1}$ at 02.00 hours and reaching $10.0 \pm 3.2 \mathrm{ml} \cdot \mathrm{kg}^{-1} \cdot \mathrm{min}^{-1}$ at 06.00 hours $(p<0.01)$. mean clearance rates for Group A were steady at $4.2 \mathrm{ml} \cdot \mathrm{kg}^{-1} \cdot \mathrm{min}^{-1}$ at both time points. Insulin infusates were sampled hourly and assayed for insulin content and no appreciable change was noted.

Comparison of free insulin concentrations by two techniques of sample preparation following subcutaneous injection of insulin in patients with Type 1 diabetes (Fig.3). Mean pre-injection free insulin values were $108 \pm$ $43 \mathrm{pmol} / \mathrm{l}(15 \pm 6 \mu \mathrm{U} / \mathrm{ml})$ and $65 \pm 14 \mathrm{pmol} / \mathrm{l}(9 \pm 2 \mu \mathrm{U} / \mathrm{ml})$ by delayed and immediate polyethylene glycol separation respectively (NS). Mean peak concentrations during the
$4 \mathrm{~h}$ following the injection were not significantly different by the two techniques, $215 \pm 57$ and $158 \pm 14 \mathrm{pmol} / \mathrm{l}$ but were each significantly higher than the pre-injection values (both $p<0.01$ ). Thus, the mean measurable increment from baseline to peak value was $108 \pm 14$ and $93 \pm 14 \mathrm{pmol} / 1 \mathrm{respectively,} \mathrm{NS}$.

Glucose turnover (Fig.4). Mean rates of glucose production and utilization fluctuated slightly but were 20 to $30 \%$ higher at every time point examined in the diabetic control group relative to those with growth hormone deficiency (NS).

Counterregulatory hormones, lactate, alanine, and $\beta$-hydroxybutyrate (Table 1 ). As expected, mean cortisol concentration increased in the Group A between 03.00 and 08.00 hours to a maximum of $700 \pm 190 \mathrm{nmol} / 1$ while only one of the Group B patients demonstrated any diurnal rise (maximum concentration of $100 \mathrm{nmol} / \mathrm{l}$ ). Glucagon concentrations appeared to be equivalent in both groups with no consistent trend to increase or decrease during the night. Epinephrine concentrations in both groups remained below $380 \mathrm{pmol} / 1$ in all individuals studied. The mean norepinephrine concentration was stable in Group A, while a gradual increase occurred in Group B to a maximum of $1.48 \pm 0.17 \mathrm{nmol} / 1$ by 07.00 hours. Lactate and alanine concentrations were not substantially different between the two groups. There was a tendency for the $\beta$-hydroxybutyrate concentration to be lower in those patients with growth hormone deficiency.

Growth hormone, NEFA, glycerol and rate of glycerol production (Fig.5). Individual peak growth hormone concentrations for Group A were between 270 and $1320 \mathrm{pmol} / \mathrm{l}$. Mean serum NEFA concentrations in

Table 1. Range of mean glucose counterregulatory hormone concentrations and intermediary metabolites (24.00 to 08.00 hours variable night)

\begin{tabular}{lll}
\hline & Group A & Group B \\
\hline $\begin{array}{l}\text { Cortisol } \\
\text { (nmol/l) }\end{array}$ & $160 \pm 20$ to $7.00 \pm 190$ & $<30$ to $40 \pm 20$ \\
$\begin{array}{l}\text { Glucagon } \\
\text { (ng/l) }\end{array}$ & $75 \pm 5$ to $105 \pm 13$ & $70 \pm 18$ to $105 \pm 16$ \\
$\begin{array}{l}\text { Epinephrine } \\
\text { (pmol/l) }\end{array}$ & $90 \pm 30$ to $140 \pm 30$ & $110 \pm 50$ to $190 \pm 120$ \\
$\begin{array}{l}\text { Norepinephrine } \\
\text { (nmol/l) }\end{array}$ & $0.74 \pm 0.17$ to & $0.81 \pm 0.17$ to \\
$\begin{array}{l}\text { Lactate } \\
\text { ( } \mu \text { mol/ })\end{array}$ & $0.99 \pm 0.14$ & $1.48 \pm 0.28$ \\
$\begin{array}{l}\text { Alanine } \\
\text { ( } \mu \text { mol/ })\end{array}$ & $582 \pm 50$ to $647 \pm 77$ & $704 \pm 57$ to $945 \pm 31$ \\
$\begin{array}{l}\beta \text {-Hydroxybutyrate } \\
\text { ( } \mu \text { mol/ })\end{array}$ & $226 \pm 27$ to $313 \pm 41$ & $301 \pm 38$ to $388 \pm 55$ \\
\hline
\end{tabular}

Group A, group of five patients with Type 1 (insulin-dependent) diabetes mellitus and chronic growth hormone and cortisol deficiency; Group B, control group of six patients with Type 1 diabetes and intact growth hormone secretion 

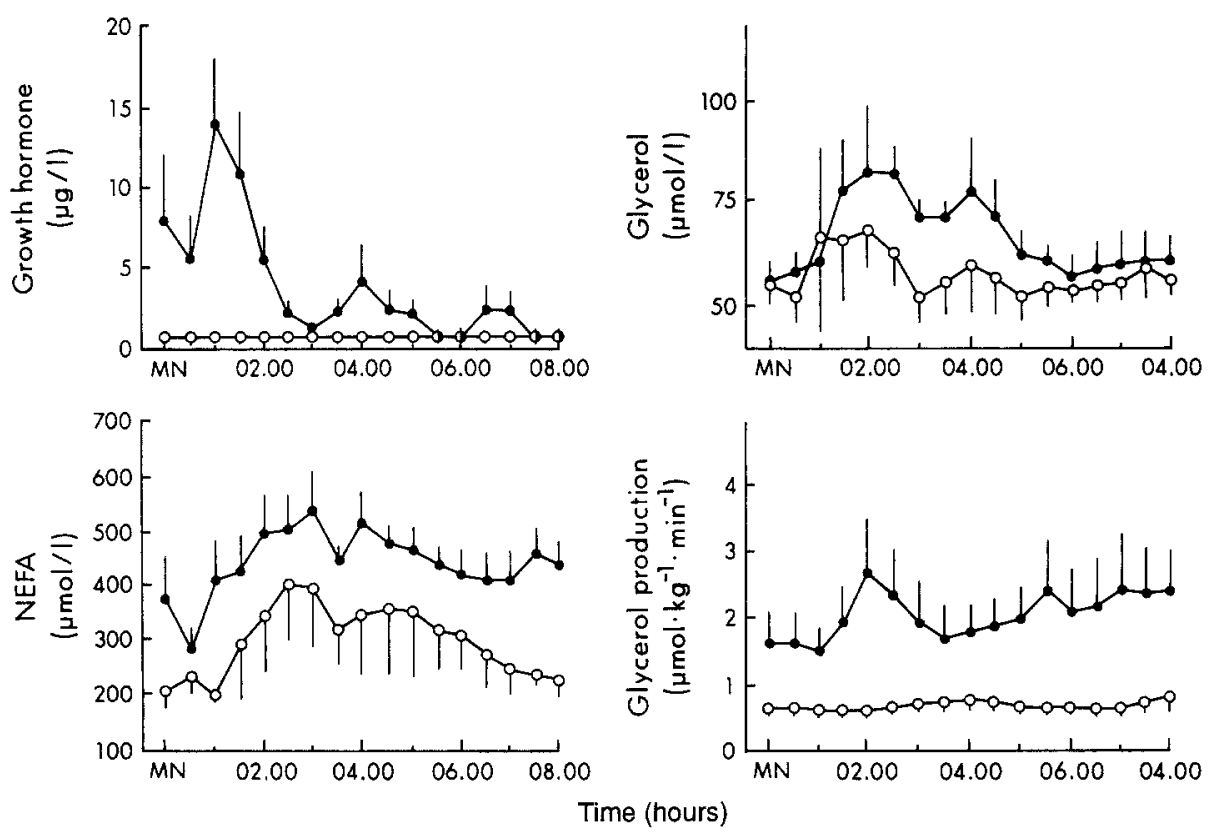

Fig. 5. Growth hormone, NEFA, glycerol and glycerol production rates mean \pm SEM during variable infusion night ( $\mathrm{MN}, 24.00$ hours) in Type 1 (insulin-dependent) diabetic patients (closed symbols) and Type 1 diabetic patients with growth hormone deficiency (open symbols)
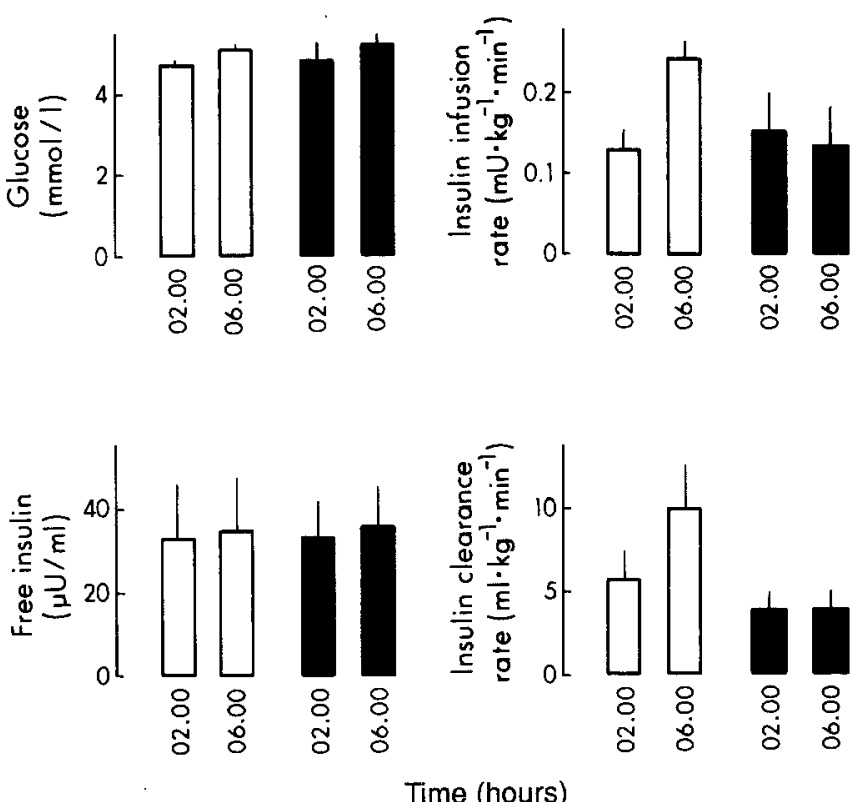

Fig. 6. Glucose concentration, insulin infusion rates, plasma free insulin, and insulin clearance rate mean \pm SEM at 02.00 and 06.00 hours in Type 1 (insulin-dependent) diabetic patients (open columns) and Type 1 diabetic patients with growth hormone deficiency (closed columns) when the insulin infusion rate was fixed at 04.00 hours

Group A were higher than Group B at all time points during the night. Areas under the curve for NEFA for each individual were significantly different between the two groups, $p<0.05$. Mean glycerol concentration increased approximately $30 \mu \mathrm{mol} / \mathrm{l}$ between 24.00 and 02.00 hours and then declined to baseline by 06.00 hours in Group A. There were no significant changes in Group B during the night and absolute mean concentration of glycerol was not different between the two groups during the dawn period ( 04.00 to 08.00 hours). Glycerol production rates were approximately three- to five-fold higher in diabetic subjects with growth hormone compared to those without, $p<0.05$.

Fixed infusion night (Fig.6). Mean plasma glucose concentration at 02.00 hours was not different between groups. By 04.00 hours glucose was stable at 5.4 $\pm 0.1 \mathrm{mmol} / \mathrm{h}$ and $5.0 \pm 0.2 \mathrm{mmol} / 1$ for Group A and B, respectively. After insulin infusion rates in the diabetic control group were fixed at $0.23 \pm 0.03 \mathrm{mU} \cdot \mathrm{kg}^{-1} \cdot \mathrm{min}^{-1}$, the plasma glucose level rose to only $5.8 \pm 0.2 \mathrm{mmol} / \mathrm{h}$ at 06.00 hours although it reached a maximum of $6.7 \pm 0.5 \mathrm{mmol} / \mathrm{l}$ by 08.00 hours (latter data not shown). Conversely, after insulin infusion rates in Group B were fixed at $0.18 \pm 0.06 \mathrm{mU} \cdot \mathrm{kg}^{-1} \cdot \mathrm{min}^{-1}$, plasma glucose fell slightly to $4.7 \pm 0.6 \mathrm{mmol} / \mathrm{l}$ at 06.00 hours and further to $4.4 \pm 0.9 \mathrm{mmol} / \mathrm{l}$ by 08.00 hours (latter data not shown). The decrements observed in Group B underestimate the true level of glycaemia that would have occurred under these conditions, as one subject in Group B had the infusion interrupted when plasma glucose reached $3.1 \mathrm{mmol} / \mathrm{l}$. Mean free insulin concentration fell slightly in Group A which had normal pituitary function while the growth hormone deficient group's mean free insulin concentration was not different at the end of the night relative to that at 02.00 or 04.00 hours. Insulin clearance appeared to increase between 02.00 and 06.00 hours but failed to achieve significance.

NEFA clamp (Fig. 7). Mean plasma glucose concentrations were well-matched on both nights in Group A patients before 02.30 hours but tended to be slightly higher between 03.00 and 06.00 hours during the night heparin was infused. The insulin infusion rate to achieve this level of glycaemia was not significantly different from the night when NEFA was not elevated by heparin. Likewise, the plasma free insulin concentrations were not significantly different between the two nights. NEFA levels increased to the desired range of $600 \mu \mathrm{mol} / 1$ until 06.00 hours when 

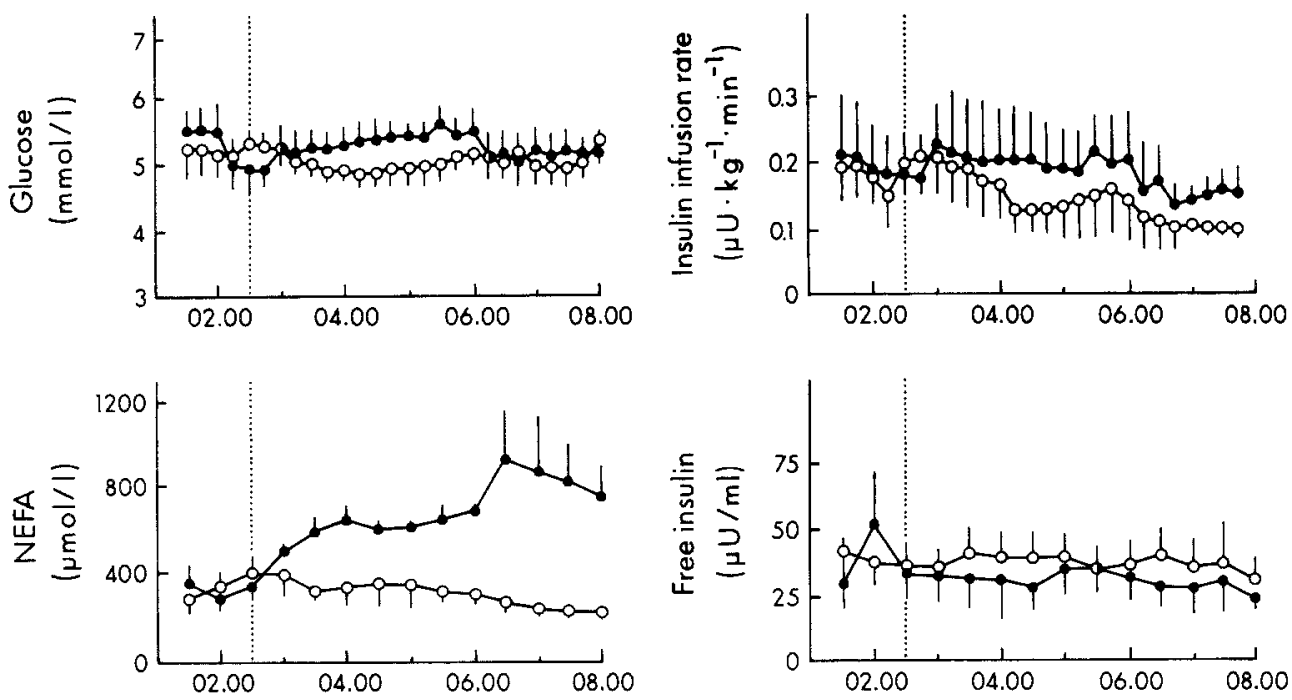

Fig. 7. Glucose concentration, insulin infusion requirements, NEFA concentrations, free insulin concen-

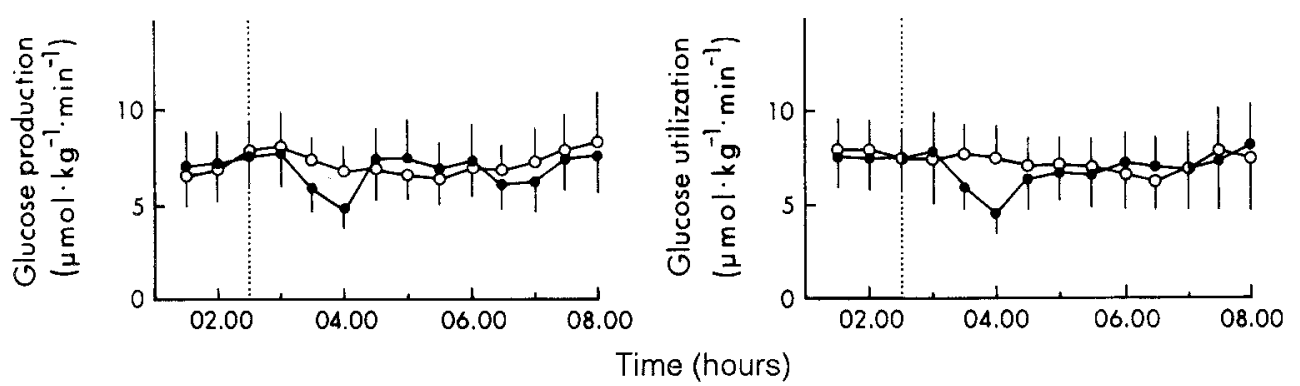
trations, glucose production and utilization mean \pm SEM with heparin infusion added (closed symbols) at 02.30 hours to variable insulin infusions in growth hormone deficient Type 1 (insulin-dependent) diabetic patients compared with $0.9 \% \mathrm{NaCl}$ infusions in the same patients

they were elevated further to approximately $800 \mu \mathrm{mol} / 1$. Both mean glucose production and utilization transiently decreased after heparin was added but returned to baseline within $2 \mathrm{~h}$ and stayed there despite further increments in NEFA in the final $2 \mathrm{~h}$.

\section{Discussion}

For over a decade the mechanisms involved in the genesis of the dawn phenomenon have been debated. Our observations are in agreement with the original conclusion of Campbell et al. [4] that growth hormone is the essential regulatory factor which somehow sets the stage for increased insulin requirements in the dawn hours. However, the relative hyperglycaemia that results from failing to match insulin requirements is at most only $2.8 \mathrm{mmol} / \mathrm{I}$ when the infusion is fixed at 04.00 hours. This figure is remarkably similar to that of approximately $2.0 \mathrm{mmol} / 1$ reported by Bolli [24]. Thus, the magnitude of the dawn phenomenon is not great.

One potential argument against concluding that growth hormone is a mediator of the dawn phenomenon from these investigations is that normal late night increments in cortisol secretion were also absent in our patients with hypopituitarism. (Glucocorticoid deficiency was managed with dexamethasone replacement so that basal requirements were met.) However, given the several hour delay in steroid hormone action following its endogenous release [25], one would not expect there to be an effect of increased nocturnal cortisol secretion until long after the dawn period. In fact, blockade of the usual morning rise in cortisol, using dexamethasone to inhibit ACTH secretion, has been shown not to alter the dawn phenomenon [4]. Additionally, blockade of cortisol synthesis during the night with metyrapone does not alter nocturnal insulin requirements in Type 1 diabetes [3]. Thus, the combination of chronic growth hormone deficiency and absence of nocturnal increments in cortisol over baseline in our patients is unlikely to have produced results different from growth hormone deficiency in isolation.

The large difference in insulin infusion rates during the final half of the night with resulting mean free insulin concentrations that were equivalent at all time points requires comment. The rate of insulin clearance (infusion rate divided by free insulin concentration) appears to have increased only in the growth hormone sufficient group. Increments in nocturnal rates of insulin clearance have been reported previously [26,27], but the validity of the observations have been questioned because of technical difficulties with the method of insulin delivery employed [28]. In the present study, insulin delivery was constant as evidenced by the measurement of constant insulin content in the infusate and infusing it by syringe pump. Thus, the critical value in calculating metabolic clearance rate of insulin becomes the plasma free insulin measurement. It has been suggested [29] that the inability of the polyethylene glycol method, used to measure plasma free insulin concentrations in samples from patients with Type 1 diabetes, to detect small differences in insulin levels in the labora- 
tories of some investigators might explain the finding of pre-breakfast increments in calculated insulin clearance. Although our current data demonstrate that the absolute concentrations of free insulin measured by the two commonly employed methods were not identical, the absolute increment that both methods are capable of detecting is equivalent. Therefore, we believe that our observed increase in clearance during the dawn period was not due to an artifact. In support of this observation, Arslanian and Ohki [30] have recently published a preliminary report showing an increased metabolic clearance rate of insulin (determined from samples precipitated for free insulin at the bedside) during the dawn period in ten adolescent diabetic patients using an experimental design similar to that employed in this study.

De Feoet al. [31] have presented strong evidence to the contrary. They examined insulin clearance during the night in patients with Type 1 diabetes and found no difference during the hours of 22.00 to 02.30 hours vs 04.00 to 08.30 hours at three different infusion rates. A potential difference between that study and our current observation is that their initial clearance measurements may have been performed too early rather than during the nadir of glucose turnover (about 03.00-05.00 hours). Also, insulin clearance rates were averaged over blocks of time in De Feo's study while the pre-breakfast peak in insulin clearance that we report was of relatively short duration and might have been missed by averaging. Recently, this study was repeated at different insulin infusion rates [32]; clearance rates, again averaged between 24.00 and 02.00 hours vs 06.00 to 08.00 hours, were not different. Likewise, Campbell and Gerich [33] found no change in insulin clearance using a continuous insulin infusion by Harvard pump. The presence or absence of altered insulin clearance in relationship to the growth hormone-related component of the dawn phenomenon remains controversial.

Growth hormone appears to be a key factor regulating lipolysis during the night in patients with insulin-dependent diabetes mellitus. Both glycerol flux and NEFA concentrations were significantly lower in the absence of growth hormone at equivalent levels of glycaemia. Despite lower rates of glycerol production, glycerol concentrations were similar between the two groups. Thus, rates of glycerol utilization must have been lower (relative to control diabetic patients) with growth hormone absent. The significance of this observation is unclear. The failure of glycerol production to increase substantially during the second half of the night in growth hormone sufficient diabetic patients is likely the result of a potent inhibition of lipolysis which appears above peripheral insulin levels of $180 \mathrm{pmol} / \mathrm{l}(25 \mu \mathrm{U} / \mathrm{ml})$ [34]. Thus, any contribution which growth hormone is likely to have made toward increments in NEFA concentrations would likely by blunted by the relative hyperinsulinaemia required to produce euglycaemia in the current study. Still, it is of interest that even in the presence of high free insulin concentrations, growth hormone provides an important positive signal for lipolysis.

Growth hormone secretion may lead to increased insulin requirements during the dawn period by elevating NEFA which compete for glucose utilization as described initially by Randle [35]. Ferrannini et al. [9] extended the observation to human subjects during euglycaemic hyperinsulinaemic clamps studies coupled with lipid infusion and observed sustained reductions in glucose disposal at NEFA concentrations which exceeded $1000 \mu \mathrm{mol} / \mathrm{l}$. Lee [10] later observed increased glucose production with normal utilization during clamp studies with insulin and NEFA concentrations similar to those seen in our patients. However, in the current studies, when low doses of heparin were administered to growth hormone deficient diabetic patients, the resulting normalization of NEFA to levels seen in the control group caused only a transient fall in peripheral glucose disposal and the amount of insulin infused to maintain euglycaemia was not increased significantly compared to nights when heparin was not given. Thus, although the number of patients studied was small, the data suggest that the growth hormone related difference in nocturnal NEFA concentration which we report does not serve as a connecting mechanism between the hormone's secretion and the dawn phenomenon.

Finally, diminished insulin sensitivity and the resultant increase in glucose production have been thought to contribute to the dawn phenomenon $[5,32,36,37]$. Continuous intravenous infusion of growth hormone for $12 \mathrm{~h}$ at rates sufficient to raise serum growth hormone concentrations into a range seen only for brief periods during sleep, results in impaired insulin-mediated glucose disposal in vivo [37]. Endogenous rates of glucose production tended to be lower in Group A suggesting a relatively heightened insulin responsiveness, but the difference was not significant. The fact that equivalent glycaemic levels were observed with nearly identical, stable insulin concentrations in both groups on the variable infusion night does not support insulin resistance as a mechanism linking growth hormone secretion to increments in insulin requirements hours later.

In summary, our finding that the dawn phenomenon does not occur in growth hormone deficient patients with Type 1 diabetes provides further evidence that nocturnal growth hormone secretion plays a key role in the pathogenesis of the dawn phenomenon in Type 1 diabetes. However, the mechanism by which growth hormone mediates this effect (e.g. through altered insulin clearance or sensitivity) remains controversial.

Acknowledgements. The authors acknowledge the technical assistance of Mr. K.Jethi, Ms. A. Bansal, Mr. G. Winter, Ms. Z. Lubovich, Ms. G. Leybovich, Ms. J.Brothers, and Mr. A. Akinola. The assistance of the nursing staff of the Washington University General Clinical Research Center, particularly Ms. C. Havlin, Ms. M. Mohr, Ms. M. Paulus, and Mr. M. Bovier are gratefully acknowledged. The secretarial assistance of Ms. R. Stoll is also acknowledged. Dr. Avogaro participated in this work as a Fogarty fellow in endocrinology and metabolism on leave from the University of Padova, Padova, Italy. Dr. Boyle was supported, in part, by a fellowship award from the American Diabetes Association. This study was supported, in part, by U.S.P.H.S. grants RR.00036, DK27085, DK20579.

\section{References}

1. Clarke WL, Haymond MW, Santiago JV (1980) Overnight basal insulin requirements in fasting insulin dependent diabetic patients. Diabetes 29: 78-80 
2. Schmidt MI, Hadji-Georgopoulos A, Rendell M, Margolis S, Kowarski A (1981) The dawn phenomenon, early morning glucose rise: implications for diabetic intraday blood glucose variation. Diab Care 4: 579-585

3. Bright GM, Melton TW, Rogol AD, Clarke WL (1980) Failure of cortisol blockade to inhibit early morning increase in basal insulin requirements in fasting Type 1 (insulin-dependent) diabetes. Diabetes 29: 662-664

4. Skor DA, White NH, Thomas L, Shah SD, Cryer PE, Santiago JV (1983) Examination of the role of the pituitary-adrenal axis, counterregulatory hormones, and insulin clearance in variable nocturnal insulin requirements in insulin-dependent diabetes. Diabetes 32: 403-407

5. Campbell PJ, Bolli GB, Cryer PE, Gerich JE (1985) Pathogenesis of the dawn phenomenon in patients with insulin-dependent diabetes mellitus. N Engl J Med 312: 1473-1479

6. Skor DA, White NH, Thomas L, Santiago JV (1985) Influence of growth hormone on overnight insulin requirements in insulindependent diabetes. Diabetes 34: 135-139

7. Mauras N, Rogol AD, Clarke WL (1986) Failure to detect the "dawn phenomenon" in non diabetic subjects with markedly different patterns of nocturnal growth hormone secretion. J Clin Endocrinol Metab 62: 975-979

8. Macgorman LR, Consoli A, Jensen MD, Miles JM (1987) Importance of growth hormone in the maintenance of basal lipolysis in normal man. Diabetes 36 [Suppl 1]: 317

9. Ferrannini E, Barrett EJ, Bevilacqua S, DeFronzo RA (1983) Effect of fatty acids on glucose production and utilization in man. J Clin Invest 72: 1737-1747

10. Lee KU, Lee HK, Koh CS, Min HK (1988) Artificial induction of intravascular lipolysis by lipid-heparin infusion leads to insulin resistance in man. Diabetologia 31: 285-290

11. Hosaka K, Kikuchi T, Mitsuhida N, Kawaguchi A (1981) A new colorimetric method for the determination of NEFAs with acylCoA synthetase and acyl-CoA oxidase. J Biochem 89: 1799-1803

12. Meng HC, Edgren B (1963) Source of plasma NEFAs in dogs receiving fat emulsion and heparin. Am J Physiol 204: 691-695

13. Nakagawa S, Nakayama H, Sasaki T et al. (1973) A simple method for the determination of serum free insulin levels in insulin-treated patients. Diabetes 22: 590-600

14. Kuzuya H, Blix PM, Horwitz DL, Steiner DN, Rubenstein AH (1977) Determination of free and total insulin and C-peptide in insulin-treated diabetic patients. Diabetes 26:22-29

15. Ensinck JW (1983) Immunoassays for glucagon. In: Lefebvre $P$ (ed) Glucagon handbook of experimental pharmacology, Vol 66. Springer-Verlag, New York, pp 203-221

16. Schalch DS, Parker ML (1964) A sensitive double antibody immunoassay for human growth hormone in plasma. Nature 203: $1141-1142$

17. Farmer RW, Pierce CE (1974) Plasma cortisol determination: radioimmunoassay and competitive protein binding compared. Clin Chem 20: 411-414

18. Shah SD, Clutter WE, Cryer PE (1985) External and internal standards in the single isotope derivative (radioenzymatic) measurement of plasma norepinephrine and epinephrine. J Lab Clin Med 106: 624 629

19. Pinter JK, Hayashi JA, Watson JA (1967) Enzymic assay of glycerol, dihydroxy-acetone, and glyceraldehyde. Arch Biochem Biophys 121: 404-414

20. Lowry OH, Passonneau JV, Hasselberger FX, Schulz DW (1964) Effect of ischemia on known substrates and cofactors of the glycolytic pathway in brain. J Biol Chem 239: 18-30

21. Cahill GF Jr, Herrera MG, Morgan AP et al. (1966) Hormonefuel interrelationships during fasting. J Clin Invest 45: 1751-1769

22. Clutter WE, Bier DM, Shah SD, Cryer PE (1980) Epinephrine plasma metabolic clearance rates and physiologic thresholds for metabolic and hemodynamic actions in man. J Clin Invest 66: 94-101
23. Beylot M, Martin C, Beaufrere B, Riou JP, Mornex R (1987) Determination of steady-state and nonsteady-state glycerol kinetics in humans using deuterium-labeled tracer. J Lipid Res 28: 414422

24. Bolli GB (1988) The dawn phenomenon: its origin and contibution to early morning hyperglycaemia in diabetes mellitus. Diabetes \& Metabolisme (Paris) 14: 675-686

25. Utter M, Scrutton M (1969) Pyruvate carboxylase. Curr Topics Cell Regul 1: 253-296

26. Skor DA, White NH, Thomas L, Santiago JV (1984) Relative roles of insulin clearance and insulin sensitivity in the pre-breakfast increase in insulin requirements in insulin-dependent diabetic patients. Diabetes 33: 60-63

27. Dux S, White NH, Skor DA, Santiago JV (1985) Insulin clearance contributes to the variability of nocturnal insulin requirement in insulin-dependent diabetes mellitus. Diabetes 34: 12601265

28. Brennan JR, Gebhart SP, Blackard WG (1985) Pump-induced insulin aggregation: a problem with the Biostator. Diabetes 34: 353-359

29. Periello G, De Feo P, Bolli G (1988) The dawn phenomenon: nocturnal blood glucose homeostasis in Type 1 (insulin dependent) diabetes mellitus. Diab Med 5: 13-21

30. Arslanian SA, Ohki Y (1988) Pathogenesis of the dawn phenomenon in adolescents with Type 1 (insulin dependent) diabetes mellitus. Clin Res 36: 809 A

31. De Feo P, Perriello G, Ventura MM et al. (1986) Studies on overnight insulin requirements and metabolic clearance rate of insulin in normal and diabetic man: relevance to the pathogenesis of the dawn phenomenon. Diabetologia 29: 475-480

32. Perriello G, De Feo P, Torlone E et al. (1990) Nocturnal spikes of growth hormone secretion cause the dawn phenomenon in Type 1 (insulin-dependent) diabetes mellitus by decreasing hepatic (and extrahepatic) sensitivity to insulin in the absence of insulin waning. Diabetologia 33: 52-59

33. Campbell PJ, Gerich JE, Cryer PE (1986) Occurrence of dawn phenomenon without change in insulin clearance in patients with insulin-dependent diabetes mellitus. Diabetes 35: 749-752

34. Nurjihan N, Campbell PJ, Kennedy FP, Miles JM, Gerich JE (1986) Insulin dose-response characteristics for suppression of glycerol release and conversion to glucose in humans. Diabetes 35: $1326-1331$

35. Randle PJ, Hales CN, Garland PB, Newsholme EA (1963) The glucose fatty-acid cycle its role in insulin sensitivity and the metabolic disturbances of diabetes mellitus. Lancet I: 785-789

36. Koivisto VA, Yki-Jarvinen H, Helve E, Karonen SL, Pelkonen R (1986) Pathogenesis and prevention of the dawn phenomenon in diabetic patients treated with CSII. Diabetes 35: 78--82

37. Perriello G, De Feo P, Torlone E et al. (1991) The dawn phenomenon in Type 1 (insulin-dependent) diabetes mellitus: magnitude, frequency, variability and dependency on glucose counterregulation and insulin sensitivity. Diabetologia 34: 21-28

38. Rizza RA, Mandarino LJ, Gerich JE (1982) Effects of growth hormone on insulin action in man mechanisms of insulin resistance, impaired suppression of glucose production and impaired stimulation of glucose utilization. Diabetes 31: 663-669

Received: 14 May 1991

and in revised form: 3 December 1991

Dr. P.J.Boyle

Division of Endocrinology, $5 \mathrm{ACC}$

University of New Mexico

School of Medicine

Albuquerque, NM 87131

USA 